Fax: + 4402075662972

E-mail: dimitrioskaragiannis@doctors.org.uk

Eye (2006) 20, 1447-1449. 10.1038/sj.eye.6702313; published online 10 March 2006

Sir,

\section{Routine follow-up after YAG laser capsulotomy for posterior capsule opacification}

A national survey found $63 \%$ of consultant ophthalmologists review their patients within the first 8 weeks after YAG laser capsulotomy for posterior capsule opacification (RCO Annual Congress Abstract, Goyal and Goel, 2003). Review after YAG laser capsulotomy is not a stipulation of current national guidelines. ${ }^{1}$ What evidence is there that follow-up is necessary?

A retrospective assessment of patient notes for 121 YAG laser capsulotomies at Queen Mary's Hospital Sidcup from July 2003 to March 2004 revealed that the vision in $81.7 \%$ of eyes was $6 / 9$ or better, where as $15.0 \%$ did not achieve $6 / 9$ due to a clear comorbidity. Of the remaining $3.3 \%$ with vision less than $6 / 9$, one patient had an inadequate capsule gap treated successfully with further laser, where as three patients had moderately reduced vision $(6 / 12-6 / 18)$ in the absence of a definitive diagnosis.

No complications were recorded at the time of laser or on review, including the $19 \%$ of cases at higher risk of complications (axial myopia, previous retinal detachment, lattice degeneration, atrophic retinal holes, glaucoma, sulcus fixated lens, or uveitis).

Despite the relatively small numbers assessed, the high rate of satisfactory outcomes and the absence of complications concur with findings already published, ${ }^{2,3}$ which affirm the efficacy and safety of YAG laser capsulotomy. Given an adequate capsulotomy gap, minimising of lens pitting, and an accurate refraction, visual outcomes for laser should be excellent, in the absence of a comorbid condition.

Even the more common complications, namely retinal detachment and cystoid macular oedema, which have an incidence of approximately $1: 100$, tend to occur after the first few months, ${ }^{4,5}$ by which time most patients without a concurrent ophthalmic problem will have been discharged from outpatient follow-up.

More infrequent complications (less than 1:600) include macular hole, cracked lens, vitreous prolapse into the anterior chamber, lens subluxation, hyphema, uveitis, pupil block, and exacerbation of local endophthalmitis, many of which, should they occur, are identifiable at the time of the laser treatment. $2,6,7$

The spike in intraocular pressure that may occur following YAG laser, of particular clinical importance in patients with glaucoma, happens in the hours immediately post-procedure. Therefore, patients should have their pressures checked and receive treatment, if required, during the same visit, rather than at a later clinic review.

In view of the available evidence, we feel routine review in the first few weeks after laser is not justifiable, and that clinical resources should be redirected to areas of greater clinical need. We affirm the national guidelines, which emphasise the importance of both warning patients about possible complications and providing an advice sheet. ${ }^{1}$ In the event of pain, an absence of improvement or indeed a worsening of vision, or symptoms of retinal detachment, patients should be encouraged to report urgently, whether it be days, weeks, months, or even years after laser treatment.

\section{References}

1 Royal College of Ophthalmologists. Management of posterior capsule opacification. In: Seward H (ed). Royal College of Ophthalmologists' Management of Cataract Surgery Guidelines London, 2004 p 34.

2 Flohr MJ, Robin AL, Kelley JS. Early complications following Q-switched neodymium: YAG laser posterior capsulotomy. Ophthalmology 1985; 92: 360-363.

3 Buehl W, Sacu S, Findl O. Association between intensity of posterior capsule opacification and visual acuity. J Cataract Refract Surg 2005; 31: 543-547.

4 Lee MS, Lass JH. Rapid response of cystoid macular edema related to Nd:YAG laser capsulotomy to $0.5 \%$ Ketorolac. Ophthalmic Surg Lasers Imaging 2004; 35: 162-164.

5 Steinert RF, Puliafito CA, Kumar SR, Dudak SD, Patel S. Cystoid macular edema, retinal detachment, and glaucoma after Nd:YAG laser posterior capsulotomy. Am J Ophthalmol 1991; 112: 373-380.

6 Winslow RL, Taylor BC. Retinal complications following YAG laser capsulotomy. Ophthalmology 1985; 92: 785-789.

7 Shah GR, Gills JP, Durham DG, Ausmus WH. Three thousand YAG lasers in posterior capsulotomies: an analysis of complications and comparison to polishing and surgical discission. Ophthalmic Surg 1986; 17: 473-477.

HJ Bunting ${ }^{1}$ and $\mathrm{H}^{2}$ Laganowski

'Department of Ophthalmology, University Hospital of Wales, Heath Park, Cardiff, Wales, UK

${ }^{2}$ Queen Mary's Hospital, Frognal Avenue Sidcup, UK

Correspondence: HJ Bunting, Cardiff Eye Unit, 
University Hospital of Wales, Heath Park,

Cardiff CF14 4XW, UK

Tel: + 442920747747 ;

Fax: + 442920748300 .

E-mail: hjbunting11@yahoo.com

Eye (2006) 20, 1449-1450. doi:10.1038/sj.eye.6702315; published online 3 March 2006

\section{Sir,}

Choroidal ganglioneuroma in a patient with neurofibromatosis type 1 : a case report

Ganglioneuromas are rare, benign tumours, forming part of a spectrum of tumours arising from primordial neural crest cells in the sympathetic nervous system. ${ }^{1}$ However, they can dedifferentiate into the malignant neuroblastoma and ganglioneuroblastoma. ${ }^{1}$ Choroidal ganglioneuroma is extremely rare. ${ }^{2}$ Herein, we report a patient with neurofibromatosis type 1 (NF-1) who underwent evisceration for a painful blind eye, subsequent histopathological examination (HPE) revealing a clinically unsuspected choroidal ganglioneuroma.

\section{Case report}

A 11-year-old boy presented with severe pain in his congenitally enlarged blind left eye. He had undergone a glaucoma filtering surgery at 1 year of age, details of which were unavailable.

Visual acuity in the normal right eye was $6 / 6$. There was an upper eyelid plexiform neurofibroma on the left side and multiple facial café-au-lait spots (Figure 1, left). The left eye was buphthalmic with multiple iris Lisch nodules and a cataractous lens precluding fundus examination. Intraocular pressure was $34 \mathrm{mmHg}$. Computed tomography (CT) scan showed an enlarged left eye. The greater wing of the sphenoid was hypoplastic (Figure 1, right). A clinical diagnosis of NF-1 with a painful blind left eye was made. As the patient desired cosmetic improvement, an evisceration with silicone implant with subsequent prosthesis fitting was considered. At surgery, there was no evident abnormal intraocular tissue.

HPE revealed thickened choroid with a cellular lesion, consisting of bundles of spindle cells admixed with clusters of ganglion cells, with no atypia, necrosis, or pleomorphism (Figure 2, left). The ganglion cells showed abundant cytoplasm, a large vesicular nucleus with prominent nucleoli and stained brightly with neuron-specific enolase (Figure 2, centre). These features were diagnostic of a benign choroidal ganglioneuroma. Immunohistochemistry with neurofilament (Figure 2, right) confirmed the presence of ganglion cells and with S-100 confirmed the neural bundles.

\section{Comment}

Patients with NF-1 have inactivation of the $17 \mathrm{q} 11$ tumour suppressor gene predisposing to tumours of neural crest origin. $^{3}$ A decrease in neurofibrin production with subsequent increase in Ras-GTPase activity causes cellular proliferation and mitosis. ${ }^{3}$

Choridal ganglioneuroma in NF-1 is very rare, with MEDLINE search revealing only one published case report. $^{2}$ In this patient also, enucleation for a painful
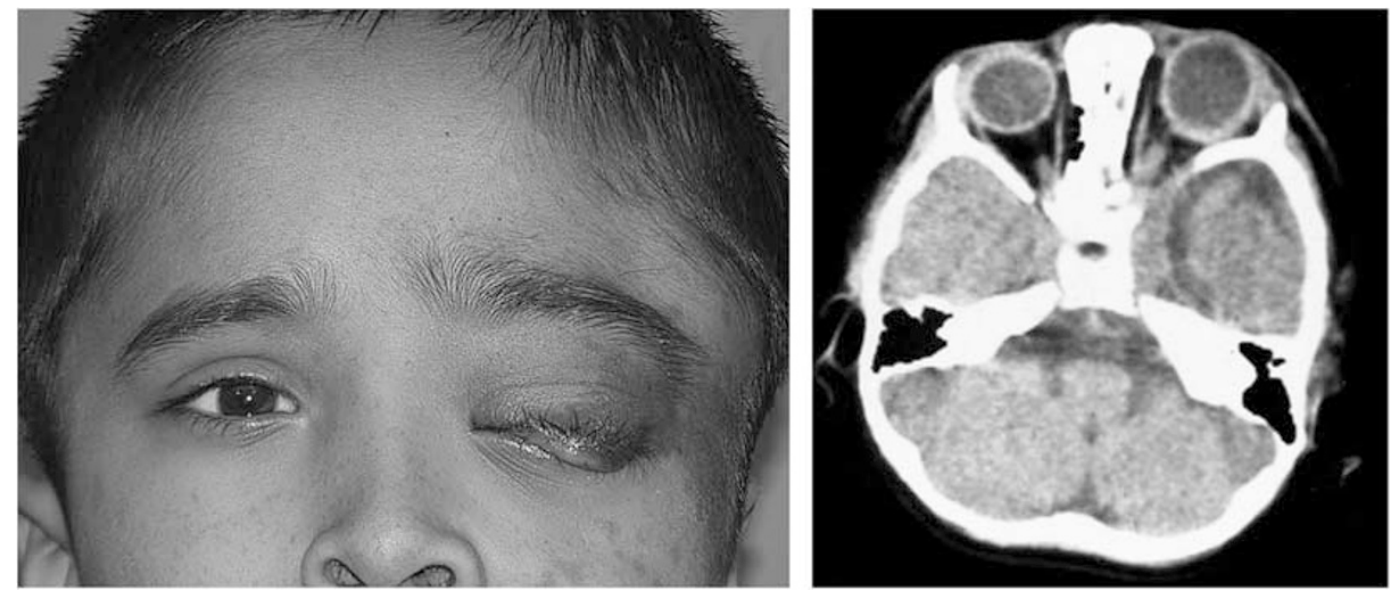

Figure 1 NF-1 with choroidal ganglioneuroma: external photograph of the face showing bupthalmos of the left eye and multiple caféau-lait spots on the face (left) and an axial CT scan showing enlargement of the left eye and absence of the greater wing of sphenoid (right). 